\title{
Correlation and Path Analysis for Yield and its Component Traits in NPT Core Set of Rice (Oryza sativa L.)
}

\author{
Rachana Bagudam ${ }^{1,2 *}$, K.B. Eswari ${ }^{1}$, Jyothi Badri ${ }^{2}$ and P. Raghuveer Rao ${ }^{2}$ \\ ${ }^{1}$ Department of Genetics and Plant breeding, College of Agriculture, PJTSAU, \\ Hyderabad-030, Telangana, India \\ ${ }^{2}$ ICAR-Indian Institute of Rice Research, Hyderabad-030, Telangana, India \\ *Corresponding author
}

\begin{abstract}
Keywords
Rice, Correlation,

PATH analysis,

New plant type,

Yield, Yield

components

\section{Article Info}

Accepted:

04 August 2018

Available Online:

10 September 2018 component traits plays a vital role in stabilizing the trait 'overall yield'. Correlation and path analysis were examined in 46 rice genotypes including tropical japonica accessions, indica land races and elite indica cultivars as New plant type (NPT) core set along with checks during kharif 2017. The data was recorded on twelve quantitative traits viz., days to $50 \%$ flowering, plant height, number of tillers, number of panicles, panicle length, panicle weight, grain number, test weight, single plant yield, plot yield, biomass and harvest index. Correlation studies revealed highly significant and positive association of single plant yield with days to $50 \%$ flowering, tillers per plant, productive tillers per plant and biomass, indicating that these characters are very important for yield improvement and concurrent selection will directly lead to high yield. Path coefficient analysis showed that productive tillers per plant exerted highest positive direct effect followed by panicle length, number of grains per panicle, test weight, panicle weight, harvest index and biomass on single plant yield, indicating that selection for these characters is likely to bring about an overall improvement in grain yield per plant directly. In view of the results obtained, it may be concluded that characters like productive tillers per plant and biomass could be used as a direct selection criteria for higher grain yield.
\end{abstract}

\section{A B S T R A C T}

Grain yield in rice is considered as a complex trait, determined by the ultimate expression of its individual component traits. Establishing an association between yield and its

\section{Introduction}

Rice is the most essential human nourishment crop in the world for direct feeding a larger number of individuals and continues to be an important area of research on global level. Asia represents 90 percent of worldwide rice utilization and the aggregate rice demand keeps on rising, which is insufficient to meet the sustenance demand for the evaluated nine billion individuals in 2050 (Khush 2005 and Ray et al., 2013). Crop yield is of prime significance to satisfy the needs attributable to steady increment in population.

Grain yield is an intricate character and determination of superior genotypes in view of yield is troublesome because of the incorporated structure of plant, in which the component characters are administered by a 
large number of genes. It has been reported to be influenced by productive tillers (Rashmi et al., 2017 and Harsha et al., 2017), panicle length and effective tillers per plant (Harsha et al., 2017), plant height (Sarawagi et al., 2016), the number of filled grains per panicle (Islam et al., 2015), 1000-grain weight (Chouhan et al., 2014), biomass, harvest index and number of tillers per plant (Patel et al., 2014), panicle weight and productive tillers (Rashmi et al., 2017) and harvest index (Dhurai et al., 2016).

The degree of relationship between traits conferring higher yield will be more helpful to choose the traits to be given significance in selection process. Positive relationship between traits will bring about concurrent change of both the traits while limiting determination to any of the related attributes. Negative relationship between traits necessitates equal weight on both the traits amid selection. At genetic level, a positive correlation occurs because of coupling period of linkage and negative correlation emerges because of repulsion phase of linkage of genes controlling two different traits (Nadarajan and Gunasekaran 2008).

Path coefficient investigation assists plant breeders in identifying traits on which selection pressure ought to be given for enhancing yield. The relationship of different component characters among themselves and with yield is very imperative for devising an effective selection criterion for yield. The total correlation between yield and component characters may be some times misleading, as it may be an over-estimate or under-estimate as a result of its relationship with other characters. Thus, indirect selection by correlated response may not be productive some times. At the point, when numerous characters are influencing a given character, splitting the total correlation into direct and indirect effects of cause as contrived by Wright (1921) would give more significant elucidation to the cause of association between the dependent variable like yield and independent variables like yield components. This sort of data will be useful in formulating the selection criteria, indicating the selection for these characters is likely to bring about on overall improvement in single plant yield directly. Accordingly, present investigation was framed to study the relationship between yield related traits to build up suitable plant attributes for selection to enhance the yield of rice.

\section{Materials and Methods}

46 rice genotypes comprising NPT core set (Jyothi et al., 2018) of tropical japonica accessions, indica land races along with checks were evaluated for yield and component traits during Kharif 2017 in Randomized Block Design (RBD) with three replications at ICAR-Indian Institute of Rice Research (ICAR-IIRR), Ramachandrapuram farm, ICRISAT campus, Hyderabad. Thirty days old seedlings were transplanted by adopting a spacing of $15 \mathrm{~cm}$ between plants and $20 \mathrm{~cm}$ between rows. Recommended agronomic and plant protection measures for raising a healthy nursery and main crop were taken up during the experiment.

Observations were recorded on five randomly selected plants in each genotype in each replication for twelve quantitative traits viz., days to fifty percent flowering (DFF), plant height $(\mathrm{PH})(\mathrm{cm})$, tillers per plant $(\mathrm{TN})$, number of panicles (PN), panicle length (PL) $(\mathrm{cm})$, panicle weight $(\mathrm{PW})(\mathrm{g})$, grain number (GN), thousand grain weight (TW) (g), single plant yield (SPY) $(\mathrm{g})$, plot yield (PY) $\left(\mathrm{kg} \mathrm{m}^{-2}\right)$, biomass $(\mathrm{BM})(\mathrm{g})$ and harvest index $(\mathrm{HI})(\%)$. The mean of five plants for each metric trait was considered for statistical analysis using WINDOSTAT software version 9.2. Correlation coefficients were calculated following Falconer and Mackay (1964) and 
path analysis by Dewey and Lu (1959). By keeping single plant yield as dependent variable and other eleven traits as independent variables, simultaneous equations which express the basic relationship between path coefficients were solved to estimate the direct and indirect effects.

\section{Results and Discussion}

\section{Correlation}

Selection based on magnitude and direction of association between yield and its component traits is very important in identifying the key characters, which can be exploited for crop improvement through suitable breeding programme. Correlation between yield and yield components were computed and the results are presented in (Table 1). In the present investigation, single plant yield exhibited positive and significant association with tillers per plant, days to $50 \%$ flowering, biomass and productive tillers per plant. Similar results were reported by Veni et al., (2013), Khare et al., (2014), Islam et al., (2015) for days to $50 \%$ flowering, Sanghera et al., (2013), Norain et al., (2014) for tillers per plant, Awaneet and Senapati (2013), Harsha et al., (2017) for productive tillers per plant and Konate et al., (2016) for biomass. These traits could be considered as the selection criteria for the improvement of grain yield in rice.

Days to $50 \%$ flowering exhibited positive and significant correlation with plant height, panicle length, plot yield, biomass and panicle weight. The results are in conformity with Aditya and Anuradha (2013) for plant height, grain yield per plant and panicle length, Patel et al., (2014) for biomass.

At the same time, DFF was significantly and negatively correlated with harvest index as reported previously by Solomon and Wegary (2016).
Plant height was significantly and positively correlated with panicle weight, biomass, panicle length, test weight and number of grains per panicle. Similar results were reported by Ranawake and Amarasinghe (2014) for panicle weight, Solomon and Wegary (2016) for biomass, Dhurai et al., (2016) and Harsha et al., (2017) for panicle length, Babu et al., (2012) and Ramya et al., (2017) for test weight and Rahman et al., (2014) for number of grains per panicle. Significant and negative correlation of plant height was observed with harvest index and number of panicles per plant. Similar findings were earlier reported by Solomon and Wegary (2016) for harvest index and Ravindra Babu et al., (2012) for number of panicles per plant.

Tillers per plant was significantly and positively correlated with plot yield, as reported by Sanghera et al., (2013), Norain et al., (2014) and productive tillers per plant as reported earlier by Aditya and Anuradha (2013) and Konate et al., (2016), whereas significantly and negatively correlated with panicle weight and test weight.

The results are in conformity with Padmaja et al., (2011) for test weight, Laxuman et al., (2011) for panicle weight.

The trait 'productive tillers per plant' were significantly and negatively correlated with panicle weight and test weight as reported by Padmaja et al., (2011) and Rahman et al., (2014). Significant and positive correlation was observed between panicle length and two traits, panicle weight and biomass. Similar results were reports by Solomon and Wegary (2016) for panicle length and biomass and Laxuman et al., (2011) for panicle length and panicle weight. However, significant and negative correlation was observed between panicle length and harvest index and similar such correlations were reported earlier by $\mathrm{Li}$ et al., (2012). 
Fig.1 Phenotypic path diagram for single plant yield in rice

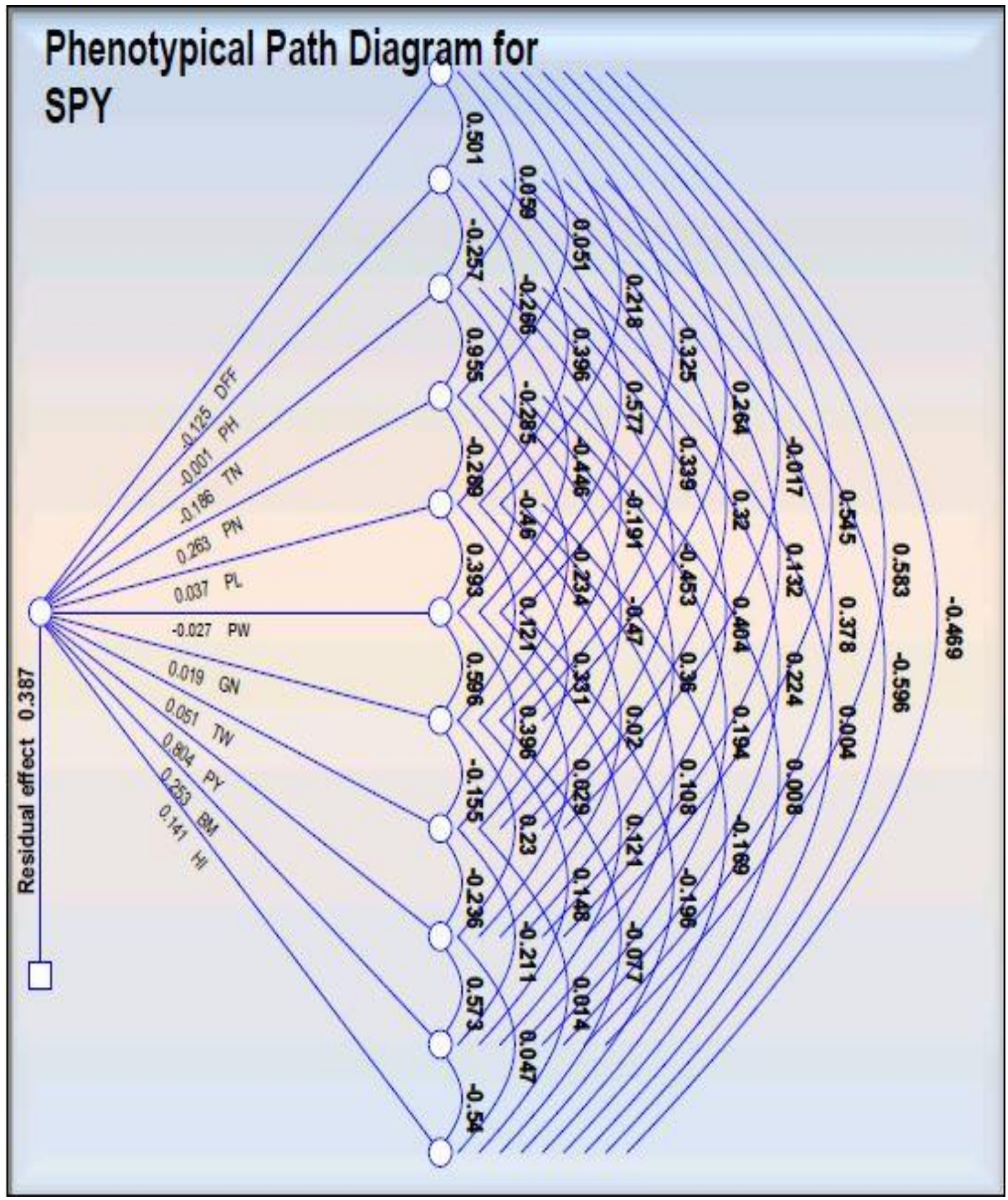


Fig.2 Genotypic path diagram for single plant yield in rice

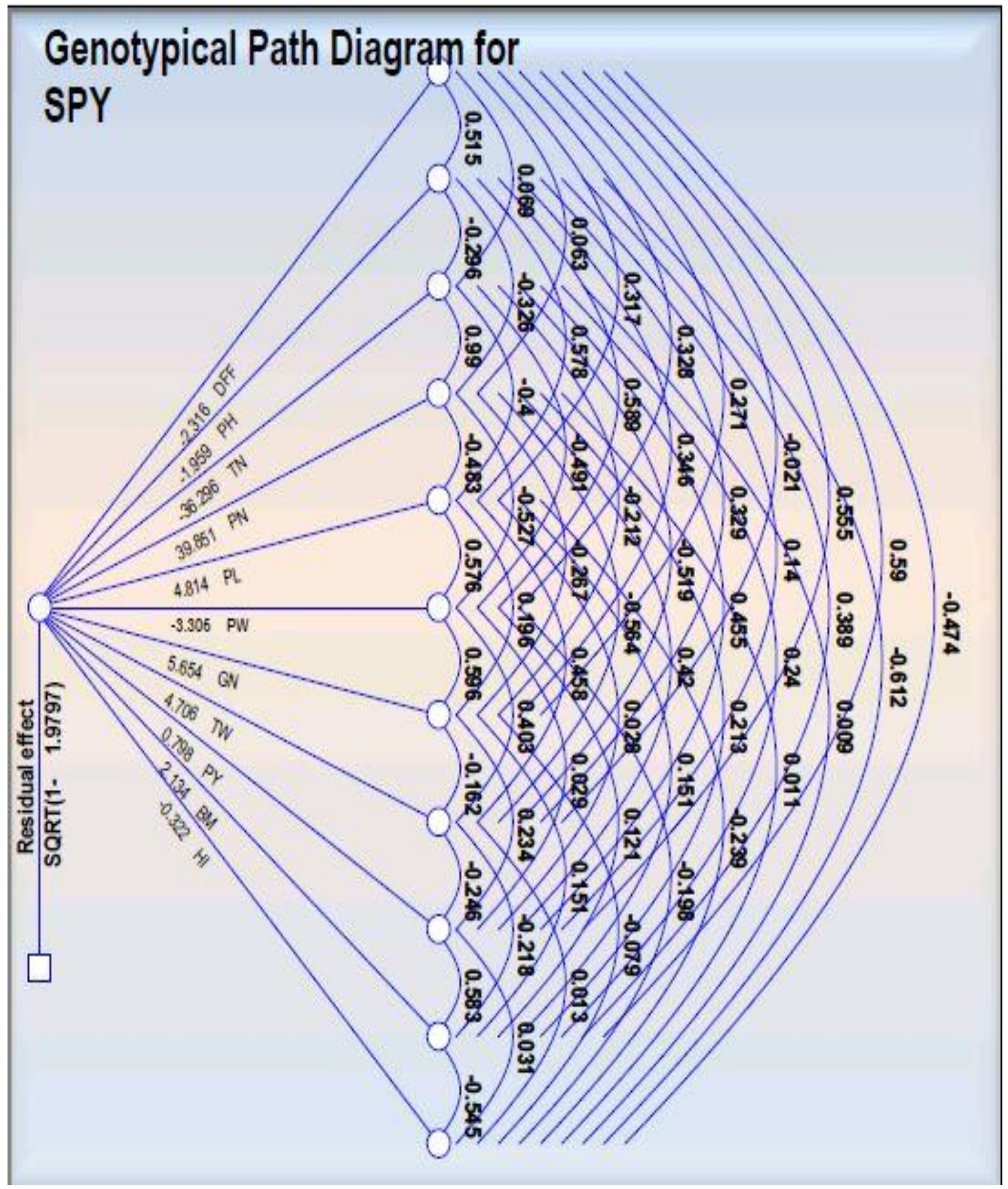


Table.1 Correlations between yield and its component traits

\begin{tabular}{|c|c|c|c|c|c|c|c|c|c|c|c|c|}
\hline Traits & DFF & PH & $\mathbf{T N}$ & $\mathbf{P N}$ & PL & PW & GN & TW & SPY & PY & $\mathbf{B M}$ & $\mathbf{H I}$ \\
\hline DFF & 1.00 & $0.51 * *$ & 0.10 & 0.06 & $0.26 * *$ & $0.32 *$ & 0.27 & -0.02 & $0.40 * *$ & $0.55 * *$ & $0.58 * *$ & $-0.47 * *$ \\
\hline PH & & 1.00 & -0.26 & $-0.29 *$ & $0.49 * *$ & $0.58 * *$ & $0.34 *$ & $0.32 *$ & 0.06 & 0.14 & $0.38 * *$ & $-0.60 * *$ \\
\hline $\mathbf{T N}$ & & & 1.00 & $0.96 * *$ & -0.32 & $-0.46 * *$ & -0.19 & $-0.48 * *$ & $0.47 * *$ & $0.46 * *$ & 0.26 & 0.01 \\
\hline $\mathbf{P N}$ & & & & 1.00 & -0.39 & $-0.49 * *$ & -0.25 & $-0.53 * *$ & $0.43 * *$ & $0.40 * *$ & 0.20 & 0.00 \\
\hline PL & & & & & 1.00 & $0.57 * *$ & 0.28 & 0.23 & 0.018 & 0.22 & $0.13 * *$ & $-0.47 * *$ \\
\hline $\mathbf{P W}$ & & & & & & 1.00 & $0.59 * *$ & $0.40 * *$ & -0.03 & 0.03 & 0.12 & -0.20 \\
\hline GN & & & & & & & 1.00 & -0.16 & 0.15 & 0.23 & 0.15 & -0.08 \\
\hline $\mathrm{TW}$ & & & & & & & & 1.00 & -0.23 & -0.24 & -0.21 & 0.01 \\
\hline SPY & & & & & & & & & 1.00 & $0.99 * *$ & $0.57 * *$ & 0.04 \\
\hline PY & & & & & & & & & & 1.00 & $0.58 * *$ & 0.04 \\
\hline $\mathbf{B M}$ & & & & & & & & & & & 1.00 & $-0.68 * *$ \\
\hline$\overline{\mathrm{HI}}$ & & & & & & & & & & & & 1.00 \\
\hline ignifica & at $5 \%$ & & & & & & & & & & & \\
\hline
\end{tabular}


Table.2 Phenotypic and Genotypic path coefficients of yield and its component traits in rice

\begin{tabular}{|c|c|c|c|c|c|c|c|c|c|c|c|c|c|}
\hline Trs & & & $\mathrm{H}$ & & $\mathrm{T}$ & L & $N$ & $\mathbf{N}$ & W & $\mathbf{Y}$ & M & HI & \\
\hline \multirow[t]{2}{*}{ DFF } & G & & 660 & 088 & 081 & -0.406 & & & & & & 6 & 0.411 \\
\hline & - & & -0.068 & 0.008 & 007 & -0.030 & & -0.036 & .002 & & -0.079 & .064 & 401 \\
\hline \multirow[t]{2}{*}{ PH } & 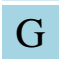 & & -0.939 & -0.278 & .306 & 0.543 & & 0.325 & 0.309 & & 0.365 & 0.575 & 062 \\
\hline & $\mathrm{P}$ & 0.001 & -0.002 & -0.001 & .001 & 0.001 & & 0.001 & 0.001 & & 0.001 & & 054 \\
\hline \multirow[t]{2}{*}{ TN } & $\mathrm{G}$ & -1.197 & & & & 6.976 & & 3.694 & 9.050 & & & & 0.481 \\
\hline & 1 & -0.012 & 0.053 & -0.207 & -0.198 & 0.059 & 092 & 0.040 & 0.094 & 084 & -0.046 & -0.001 & 0.415 \\
\hline \multirow[t]{2}{*}{ PN } & $\mathrm{G}$ & 1.153 & -5.982 & 18.15 & 18.34 & -8.857 & -9.669 & -4.897 & -10.35 & 10 & 3.907 & 0.205 & 0.467 \\
\hline & $\mathrm{P}$ & & -0.072 & & & & & & & & & & \\
\hline \multirow[t]{2}{*}{ PL } & G & 0.802 & & & & 2.533 & & & & & 0.383 & & 0.023 \\
\hline & $\mathrm{P}$ & 0.010 & 0.017 & -0.013 & -0.013 & 0.044 & 0.017 & 0.005 & 0.015 & 001 & 0.005 & -0.007 & 0.015 \\
\hline \multirow[t]{2}{*}{ PW } & G & -0.470 & -0.845 & 0.703 & & -0.825 & & -0.854 & -0.578 & .041 & -0.174 & 0.284 & -0.036 \\
\hline & $\mathrm{P}$ & & & & & -0.009 & & & & & -0.003 & & -0.034 \\
\hline \multirow[t]{2}{*}{ GN } & G & & & & & & & & & & & & \\
\hline & $\mathrm{P}$ & 0.005 & 0.006 & -0.003 & -0.004 & 0.002 & 0.010 & 0.017 & -0.003 & .004 & 0.003 & -0.001 & 0.152 \\
\hline \multirow[t]{2}{*}{ TW } & $\mathrm{G}$ & -0.039 & & & & & & & & & -0.401 & & -0.243 \\
\hline & $\mathrm{P}$ & -0.001 & 0.015 & & & 0.015 & & & & & -0.010 & 01 & -0.230 \\
\hline \multirow[t]{2}{*}{ PY } & G & & & & & & & & & & & & 0.905 \\
\hline & $\mathrm{P}$ & 0.443 & 0.107 & & & 0.017 & & & -0.192 & & & 0.038 & 0.900 \\
\hline \multirow[t]{2}{*}{ BM } & $\mathrm{G}$ & 0.308 & 0.203 & & & 0.079 & 0.063 & 0.079 & -0.114 & & 0.522 & -0.285 & 0.582 \\
\hline & $\mathrm{P}$ & 0.148 & 0.096 & & & 0.027 & & 0.038 & -0.054 & & & & 0.567 \\
\hline \multirow[t]{2}{*}{ HI } & G & -0.532 & & & & -0.268 & & & & & -0.612 & & 0.085 \\
\hline & $\mathrm{P}$ & -0.056 & -0.071 & 0.000 & 0.001 & -0.020 & -0.023 & -0.009 & 0.002 & 0.006 & -0.065 & 0.120 & 0.101 \\
\hline
\end{tabular}

Bold values are direct effects; $\mathrm{G}$ - Genotypic correlation coefficient; P - Phenotypic correlation coefficient 
Panicle weight was significantly and positively correlated with number of grains per panicle and test weight. The results are in conformity with Akinwale et al., (2011) and Ranwake and Amarasighe (2014) for number of grains per panicle and Gour et al., (2017) for test weight. Single plant yield was significantly and positively correlated with plot yield and biomass. The results are in conformity with Konate et al., (2016) for biomass. Plot yield was significantly and positively correlated with biomass. Biomass was significantly and negatively correlated with harvest index as also reported earlier by Solomon and Wegary (2016).

\section{Path coefficient analysis}

The genetic architecture of grain yield is based on the overall net effect delivered by various yield components interacting with one another. The association of different component characters among themselves and with yield is quite important for conceiving an efficient selection criterion for yield. Correlation gives only the relation between two variables, whereas path coefficient analysis allows separation of the direct effect and their indirect effects through other attributes by partitioning the correlations (Wright, 1921). In view of the data presented the genotypic and phenotypic correlations were estimated to determine direct and indirect effects of yield and yield contributing characters. If the correlation coefficient between a casual factor and the effect is almost equal to its direct effect, it explains the true relationship and a direct selection through this trait may be useful.

If the correlation coefficient is positive, but the direct effect is negative or negligible, the indirect effects appear to be the cause of that positive correlation. In such circumstance, the other factors are to be considered simultaneously for selection. However if the correlation coefficient is negative but direct effect is positive and high, a restriction has to be imposed to nullify the undesirable indirect effects in order to make use of direct effect.

Path coefficient analysis (Table 2) revealed that productive tillers per plant exerted highest positive direct effect followed by panicle length, number of grains per panicle, test weight, panicle weight, harvest index and biomass on the single plant yield indicating that selection for these characters is likely to bring about an overall improvement in grain yield per plant directly. The phenotypic and genotypic path diagrams are presented in figures 1 and 2 respectively. The results are in conformity with Kole et al., (2008), Ambili and Radhakrishnan (2011), Rangare et al., (2012), Awaneet and Senapati (2013), Berhanu et al., (2013), Chouhan et al., (2014), Naseem et al., (2014), Sarawagi et al., (2016) and Rashmi et al., (2017) for productive tiller number, Chakraborty et al., (2010), Yadav et al., (2011), Rangare et al., (2012), Awaneet and Senapati (2013), Chouhan et al., (2014), Dhurai et al., (2016), Sarawagi et al., (2016), Rashmi et al., (2017), Gour et al., (2017) and Harsha et al., (2017) for panicle length, Chakravorty and Ghosh (2012), Awaneet and Senapati (2013), Rashmi et al., (2017) and Gour et al., (2017) for panicle weight, Kole et al., (2008), Khan et al., (2009), Pankaj et al., (2010), Aditya and Anuradha (2013), Naseem et al., (2014), Patel et al., (2014), Islam et al., (2015), Dhurai et al., (2016) and Rashmi et al., (2017) for grain number, Kole et al., (2008), Chakraborty et al., (2010), Yadav et al., (2011), Rangare et al., (2012), Chouhan et al., (2014), Dhurai et al., (2016) and Rashmi et al., (2017) for test weight, Ambili and Radhakrishnan (2011) and Patel et al., (2014) for biomass and Ambili and Radhakrishnan (2011), Yadav et al., (2011), Rangare et al., (2012), Rai et al., (2014), Patel et al., (2014), Dhurai et al., (2016) and Gour et al., (2017) for harvest index. 
The traits days to $50 \%$ flowering, plant height and tillers number exerted negative direct effect on single plant yield. The results are in conformity with Ambili and Radhakrishnan (2011), Yadav et al., (2011), Babu et al., (2012), Rashmi et al., (2017) and Gour et al., (2017) for days to 50\% flowering, Babu et al., (2012), Awaneet and Senapati (2013) for plant height and Gour et al., (2017) for tillers number. The residual effect at phenotypic level was 0.386 and genotypic level was 0.826 .

The correlation studies revealed that single plant yield exhibited significant positive association with days to $50 \%$ flowering, tillers per plant, productive tillers per plant and biomass, indicating that these characters are very important for yield improvement and simultaneous selection will ultimately lead to high yield. Path coefficient analysis revealed that productive tillers per plant exerted highest positive direct effect followed by panicle length, number of grains per panicle, test weight, panicle weight, harvest index and biomass on single plant yield, indicating that selection for these characters is likely to bring about an overall improvement in grain yield per plant directly. Further, studies on correlation and path co-efficient analysis revealed the importance of productive tillers per plant and biomass, which showed highly significant positive correlation and positive direct effect with single plant yield, thus can be used as selection criteria for effective yield improvement.

\section{References}

Aditya, J.P and Anuradha, B. 2013. Genetic variability, correlation and path analysis for quantitative characters in rain-fed upland rice of Uttarakhand hills. Journal of Rice Research. 6(2): 24-34.

Akinwale, M.G., Gregorio, G., Nwilenel, F., Akinyele, B.O., Ogunbayo, S.A and
Odiyi, A.C. 2011. Heritability and correlation coefficient analysis for yield and its components in rice. African Journal of Plant Science. 5(3): 207-212.

Ambili, S.N and Radhakrishnan, V.V. 2011. Correlation and path analysis of grain yield in rice. Gregor Mendel Foundation Proceedings. 1-6.

Awaneet, K and Senapathi, B.K. 2013. Genetic parameters and association studies for important quantitative traits in advanced lines of Sambamahsuri derivatives. Journal of Crop and Weed. 9(1): 156-163.

Berhanu, D.B., Naveen, G.K., Rakhi, S and Shashidhar, H. E. 2013. Genetic evaluation of recombinant inbred lines of rice for grain zinc concentrations, yield related traits and identification of associated SSR markers. Pakistan Journal of Biological science. 16(23): 1714-1721.

Chakraborty, S., Das, P.K., Guha, B., Sarmah, K.K and Barman B. 2010. Quantitative genetic analysis for yield and yield components in boro rice (Oryza sativa L.). Notulae Scientia Biologicae. 2(1): 117-120.

Chakravorty, A and Ghosh, P.D. 2012. An analysis on genetic parameters of different Land races of rice of West Bengal. Journal of Crop and Weed. 7(2): 59-63.

Chouhan, S.K., Singh, A.K., Singh, A., Singh, N.K. Yadav, S.K and Singh, P.K. 2014. Genetic variability and association analysis in wild rice (Oryzav nivara and Oryza rufipogon). Annals of Plant and Soil Research. 16(3): 219-223.

Dhurai, S.Y., Reddy, D.M and Ravi, S. 2016. Correlation and path analysis for yield and quality characters in rice (Oryza sativa L.). Rice Genomics and Genetics. 7(4): 1-6.

Gour, L., Koutu, G.K., Singh, S.K., Patel, D.D., Shrivastava, A and Singh, Y. 
2017. Genetic variability, correlation and path analyses for selection in elite breeding materials of rice (Oryza sativa L.) genotypes in Madhya Pradesh. The Pharma Innovation Journal. 6(11): 693696.

Harsha, Deo, I., Kumar, S and Talha, M. 2017. Assessment of Genetic Variability and Inter-Character Association Studies in Rice Genotypes (Oryza sativa L.). International Journal of Current Microbiology and Applied Sciences. 6(9): 2041-2046.

Islam, M.A., Raffi, S.A., Hossain, M.A and Hasan, A.K. 2015. Character Association and Path Coefficient Analysis of Grain Yield and Yield Related Traits in Some Promising Early to Medium Duration Rice Advanced Lines. International Journal of Experimental Agriculture. 5(1): 8-12.

Jyothi, B., Divya, B., Subba Rao, L. V., Laxmi Bhavani, P., Revathi, P., Raghuveer Rao, P., Rachana, B., Padmavathi, G., Aravind Kumar, J., Gireesh, C., Anantha, M. S., Abdul Fiyaz, R., Suvarna Rani, C and Ranganatha, A.R.G. 2018. New plant type trait characterization and development of core set among indica and tropical japonica genotypes of rice. Plant Genetic Resources. 1-9. doi:10.1017/S1479262118000084.

Khan, A.S., Imran, M and Ashfaq, M. 2009. Estimation of genetic variability and correlation for grain yield components in rice. American-Eurasian Journal Agriculture \& Environmental Science. 6(5): 585-590.

Khare, R., Singh, A.K., Eram, S and Singh, P.K. 2014. Genetic variability, association and diversity analysis in upland Rice (Oryza sativa L). SAARC Journal of Agriculture. 12(2): 40-51.
Khush, G.S. 2005. What it will take to feed 5.0 billion rice consumers in 2030 . Plant Molecular Biology. 59(1):1-6.

Kole, P.C., Chakraborty, N.R and Bhat, J.S. 2008. Analysis of variability, correlation and path coefficients in induced mutants of aromatic nonbasmati rice. Eco-friendly Agriculture Journal. 113: 60-64.

Konate, A.K., Zongo, A., Kam, H., Sanni, A and Audebert, A. 2016. Genetic variability and correlation analysis of rice (Oryza sativa L.) inbred lines based on agro-morphological traits. African Journal of Agricultural Research. 11(35): 3340.

Krishna Veni, B., Vijaya Lakshmi, B and Ramana, J.V. 2013. Variability and Association Studies for Yield Components and Quality Parameters in Rice Genotypes. Journal of Rice Research. 6(2): 16-23.

Laxuman, Salimath, P.M., Shashidar, H.E., Mohankumar, H.D., Patil, S.S., Vamadevaiah, H.M and Janagouder, H.M. 2011. Character association and path coefficient analysis among the backcross inbred lines derived from indica $x$ NERICA cross for productivity traits in rice (Oryza sativa L.). Karnataka Journal of Agricultural Sciences. 24(5): 626-628.

Li, X., Yan, W., Agrama, H., Jia, L., Jackson, A., Moldenhauer, K and Wu, D. 2012. Unraveling the Complex Trait of Harvest Index with Association Mapping in Rice (Oryza sativa L.). PLoSONE. 7(1).

Nadarajan N and Gunasekaran M. 2008. Quantitative genetics and biometrical techniques in plant breeding. Kalyani Publishers, Ludhiana. pp 207.

Naseem, I., Khan, A.S and Akhter, M. 2014. Correlation and path coefficient studies of some yield related traits in rice (Oryza sativa L.). International Journal 
of Scientific and Research Publications. 4(4): 2250-3153.

Norain, M.N., Shamsiah, A., Abdul, R.H., NorAishah, H., Haslinda, A.M and Wan Aminuddin, W.A. 2014. Correlation analysis on agronomic characters in $\mathrm{F}_{2}$ population derived from MR64 and pongsu seribu2. Journal of Applied Science and Agriculture. 9(18): 143147.

Padmaja, D., Radhika, K., Rao, L.V.S and Padma, V. 2011. Correlation and path analysis in rice germplasm. Oryza. 48(1): 69-72.

Pankaj, G., Pandey, D.P and Dhirendra, S. 2010. Correlation and path analysis for yield and its components in rice (Oryza sativa L.). Crop Improvement. 37(1): 46-51.

Patel, J.R., Saiyad, M.R., Prajapati, K.N., Patel, R.A and Bhavani, R.T. 2014. Genetic variability and character association studies in rainfed upland rice (Oryza sativa L.). Electronic Journal of Plant Breeding. 5(3): 531537.

Rahman, M.M, Syed, M.A, Akter, A., Alam, M.M and Ahsam, M.M. 2014. Genetic variability, correlation and path coefficient analysis of morphological traits in transplanted aman-rice (Oryza sativaL.). American-Eurasian Journal of Agricuture \& Environmental Science. 14(5): 387-39.

Rai, S.K., Suresh B.G., Rai, P.K., Lavanya, G.R., Kumar, R and Sandhya. 2014. Genetic Variability, Correlation and Path Coefficient Studies for Grain Yield and Other Yield Attributing Traits in Rice (Oryza sativa L.). Indian Journal of Life Sciences. 2(4): 229234.

Ramya, R., Sanjeeva Rao, D., Ravindra Babu, V and Bharathi, M. 2017. Correlation and Path Coefficient Analysis for Yield, Yield Attributing and Nutritional Traits in Rice (Oryza sativa L.). International Journal of Current Microbiology and Applied Sciences. 6(11): 183-188.

Ranawake, A.L and Amarasinghe, U.G.S. 2014. Relationship of yield and yield related traits of some traditional rice cultivars in Srilanka as described by correlation analysis. Journal of Scientific Research \& Reports. 3(18): 2395-2403.

Rangare, N.R., Krupakar, A., Ravichandra, K., Shukla, A.K and Mishra, A.K. 2012. Estimation of characters association and direct and indirect effects of yield contributing traits on grain yield in exotic and Indian rice germ-plasm. International Journal of Agricultural Science. 2(1): 54-61.

Rashmi, D., Saha, S., Loitongbam, B., Singh, $S$ and Singh, P.K. 2017. Genetic Variability Study for Yield and Yield Components in Rice (Oryza sativa L.). International Journal of Agriculture, Environment and Biotechnology. 10(2): 171-176.

Ravindra Babu, V., Shreya, K., Kuldeep, S. D., Usharani, G and Siva Shankar, A. 2012. Correlation and path analysis studies in popular rice hybrids of India. International Journal of Scientific and Research Publications. 2(3): 1-5.

Ray, D.K., Mueller, N.D., West, P.C and Foley, J.A. 2013. Yield trends are insufficient to double global crop production by 2050. PLoS One. 8(6): e66428.

Sanghera, G.S., Kashyap, S.C., Parray, G.A. 2013. Genetic variation for grain yield and related traits in temperate red rice (Oryza sativa L.) ecotypes. Notulae Scientia Biologicae. 5(3): 400-406.

Sarawagi A. K., Ojha G.C., Koshta, N and Pachauri, A. 2016. Genetic Divergence and Association Study for Grain Yield in Rice (Oryza sativa L.) Germplasm accessions. The Ecoscan. 9(2): 217-223. 
Singh, C.M., Suresh Babu, G., Kumar, B and Mehandi, S. 2013. Analysis of quantitative variation and selection criteria for yield improvement in exotic germplasm of upland rice (Oryza Sativa L.). The Bioscan. 8(2): 485-492.

Solomon, H and Wegary, D. 2016. Phenotypic Correlation and Path Coefficient Analysis of Yield and Yield Component in Rice (Oryza sativa).
International Journal of Research and Review. 3(7): 1-5.

Wright, S. 1921. Correlation and causation. Journal of Agricultural Research. 20: 557-585.

Yadav, S.K., Pandey, P., Kumar, B and Suresh, B.G. 2011. Genetic architecture, Inter-relationship and selection criteria for yield improvement in rice. Pakistan Journal of Biological Sciences. 14(9): 540-545.

\section{How to cite this article:}

Rachana Bagudam, K.B. Eswari, Jyothi Badri and Raghuveer Rao, P. 2018. Correlation and Path Analysis for Yield and its Component Traits in NPT Core Set of Rice (Oryza sativa L.). Int.J.Curr.Microbiol.App.Sci. 7(09): 97-108. doi: https://doi.org/10.20546/ijcmas.2018.709.013 